SUPPLEMENTARY MATERIALS FOR

\title{
Ultrasound-aided targeting nanoparticles loaded with miR-181b for anti-inflammatory treatment of TNF-a-stimulated endothelial cells
}

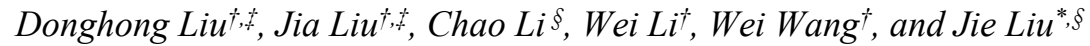

$\dagger$ Department of Medical Ultrasonics, The First Affiliated Hospital of Sun Yat-sen University, Guangzhou, Guangdong 510080, China

$\S$ School of Biomedical Engineering, Sun Yat-sen University, Guangzhou, Guangdong 510006, China

${ }^{\sharp}$ These authors contribute equally to this work.

* To whom correspondence may be addressed. E-mail: liujie56@mail.sysu.edu.cn 


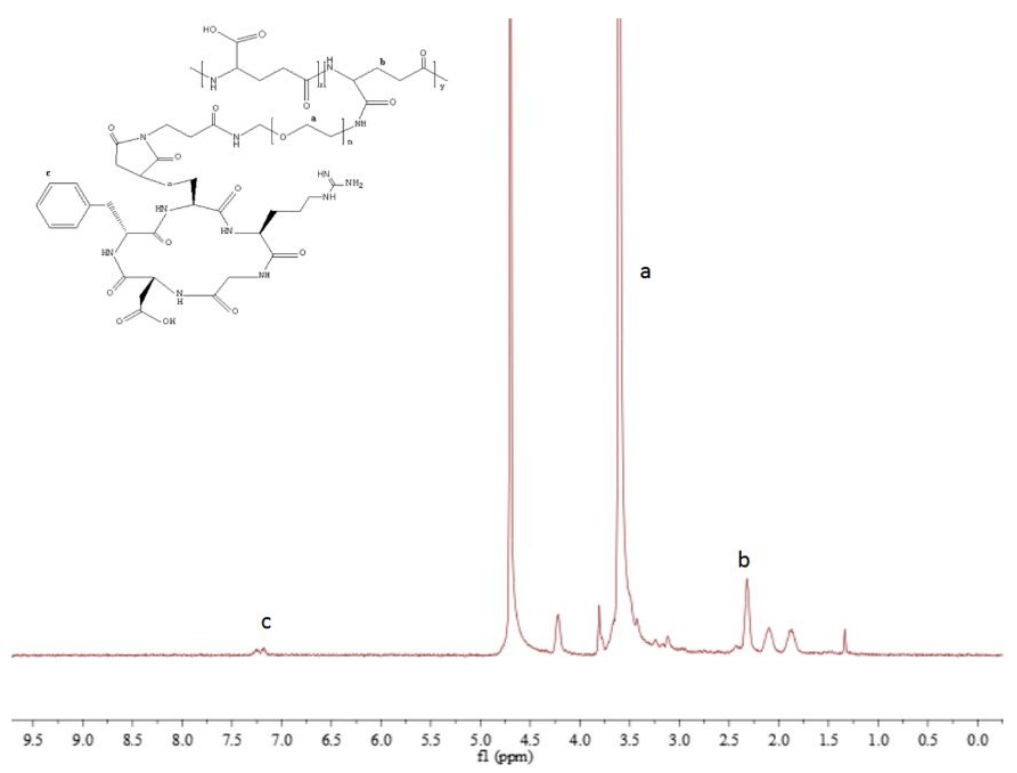

Figure S1. ${ }^{1} \mathrm{H}$ NMR spectra of PGA-g-PEG-RGD.

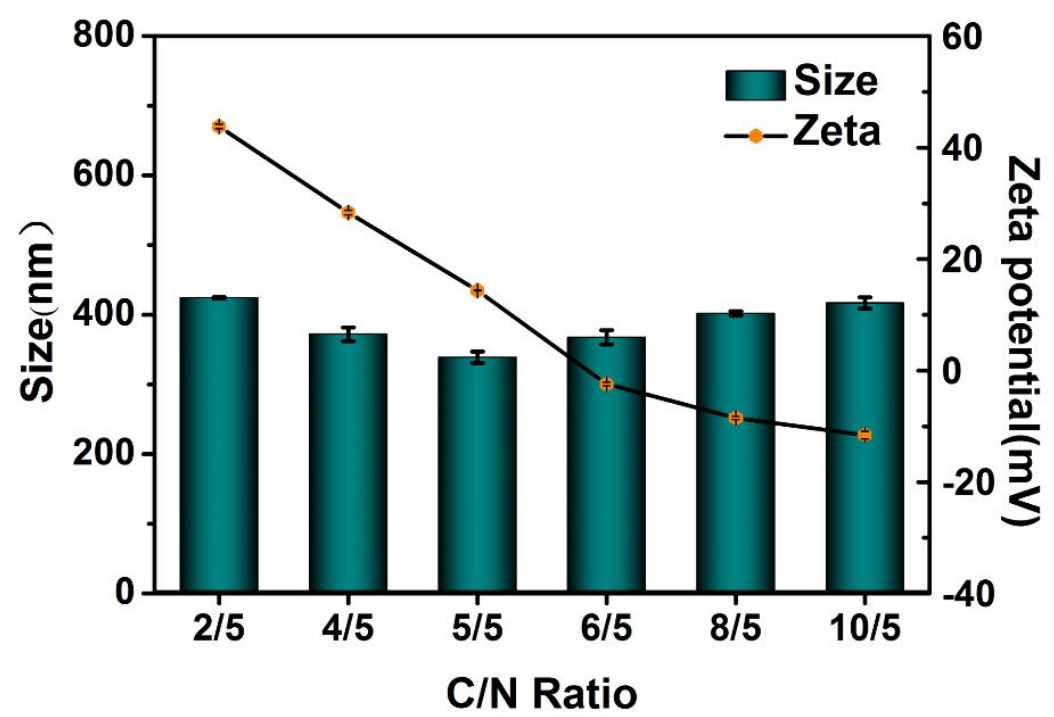

Figure S2. Particle size and zeta potential of RGD-PFP-TNDs at different $\mathrm{C} / \mathrm{N}$ ratios. 


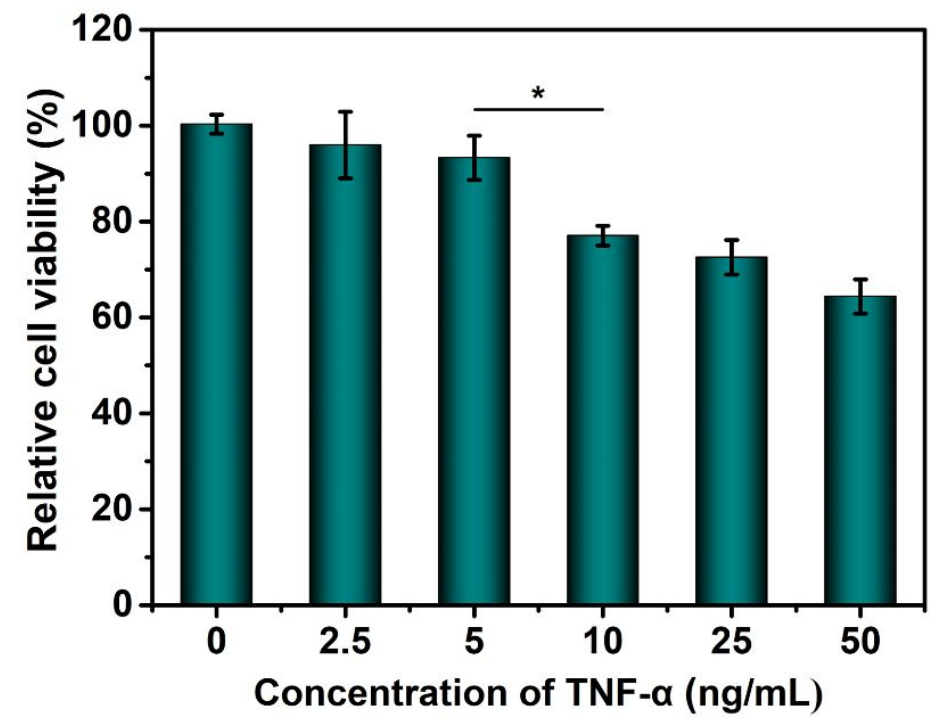

Figure S3. Cell viability induced by different concentrations of TNF-a. ${ }^{*} p<0.05$.

Table S1. Characterization of PFP-BNDs and RGD-PFP-TNDs loaded with miR-181b $\operatorname{mimic} / \mathrm{NC}(\mathrm{n}=3)$.

\begin{tabular}{lccc}
\hline \multicolumn{1}{c}{ Sample } & Size $(\mathrm{nm})$ & PDI & $\begin{array}{c}\text { Zeta Potential } \\
(\mathrm{mV})\end{array}$ \\
\hline PFP-BNDs (mimic) & $430 \pm 20$ & 0.059 & $55.1 \pm 1.1$ \\
PFP-BNDs (NC) & $423 \pm 17$ & 0.284 & $52.9 \pm 0.5$ \\
RGD-PFP-TNDs (mimic) & $368 \pm 11$ & 0.104 & $16.3 \pm 0.3$ \\
RGD-PFP-TNDs (NC) & $358 \pm 19$ & 0.148 & $14.0 \pm 0.8$ \\
\hline
\end{tabular}

